\title{
PREPARATION AND CHARACTERIZATION OF CO-CRYSTALS OF DIACEREIN
}

\author{
Raju Rameshrao Thenge*, VB. Patond ${ }^{1}$, Vaibhav Suresh Adhao ${ }^{1}$, Prashant \\ Vishnupant Ajmire ${ }^{1}$, Laxmikat Niranjan Barde, Nilesh M. Mahajan², Nilesh P. \\ Tekade $^{3}$
}

\begin{abstract}
1. Department of Industrial Pharmacy, IBSS College of Pharmacy, Malkapur-443101, Maharashtra, India.

2. Department of

Pharmaceutics, Dadasaheb Balpande College of

Pharmacy, Nagpur-440034, Maharashtra, India.

3. SGSPS Institute of

Pharmacy, kaulkhed, Akola-

444004, Maharashtra, India
\end{abstract}

Submitted: $10-12-2016$

Revised: 02-01-2017

Accepted: 05-01-2017

*Corresponding author

Raju Rameshrao Thenge

Email:

rajuthenge11@gmail.com

\begin{abstract}
Diacerein, an anti-inflammatory drug used in the treatment of osteoarthritis. Being a BCS class II drug, it has poor solubility, dissolution rate, and other physicochemical properties. Thus the aim of present study was to prepare co-crystals of diacerein to improve solubility and dissolution rate. The diacerein co-crystals were prepared using urea and tartaric acid as conformer by Solvent drop grinding method. The diacerein cocrystals were characterized by scanning electron microscopy (SEM), Fourier Transform Infrared Spectroscopy (FT-IR), Differential scanning calorimetry (DSC) and X-ray diffractometry (XRD). The co-crystals were evaluated for solubility, dissolution rate, and other physicochemical properties and compared with commercial diacerein. The co-crystals exhibit the difference in the size and shape of crystals. The FT-IR spectra of diacerein cocrystals showed slightly different in the characteristic peaks compared to commercial diacerein sample. DSC data indicate the decrease in the melting endotherm of co-crystals compares to diacerein. The co-crystals with urea showed an increase and intense peak and co-crystals with tartaric acid showed decreased number of peaks compared to commercial diacerein. The cocrystals of diacerein formulated into the Tablet and evaluated for tablet properties. The tablet formulation showed improved tablet characteristics as well as dissolution rate compared to commercial diacerein.
\end{abstract}

Keywords: Co-crystals, Diacerein, physicochemical properties, FT-IR

\section{INTRODUCTION}

Crystal habit and internal structure of a drug can affect bulk and physicochemical properties, which range from the flowability to chemical stability. Crystals are characterized by the repetitious spacing of constituent atoms or molecules in a three-dimensional array, whereas amorphous forms have atoms or molecules randomly placed as in a liquid. Crystallization is a spontaneous arrangement of particles to a repetitive ordered array i.e. regular geometrical pattern (Subrahmanyam et al., 2000). When applied solid the adjective crystalline, implies an ideal crystal in which structural units termed unit cells are repeated regularly and indefinitely in three dimensions in a space (Vippagunta $e t$ al., 2001). An ideal crystal is constructed by the regular spatial repetition of identical structural units (Saifee et al., 2009) Crystal form can be crucial to the performance of dosage form (Hickey et al., 2007)

Over the last decade, there has been growing interests in the design of pharmaceutical co- crystals, which has emerged as a potential method for enhancing the bioavailability of drug with low solubility (Bittain et al., 2006). To start with, it is necessary to important definitions: co-crystal and pharmaceutical co- crystals. Co-crystal can be defined in a number of ways. A restrictive definition utilized by that co-crystals are structurally homogenous crystalline materials containing two or more components present in definite stoichiometric amounts. The cocrystals components are discrete neutral molecular reactants which are solid at ambient temperature (Gagniere et al., 2009). Based on this definition of co-crystal, a pharmaceutical 
co- crystal means co- crystals with one of the co-crystal components as an Active Pharmaceutical Ingredient (API) and other components are called conformers. From these definitions, it is clearly shown that an API hydrate is not co-crystal; however solid-state API hydrate can cocrystallized with a solid conformer to form co-crystal (Lachman et al., 1991). Co-crystal represents a class of compound which offers huge opportunities for the pharmaceutical industry (Yadav et al., 2012). Diacerein, an anti-inflammatory drug used in the treatment of osteoarthritis. Being a BCS class II drug, it has poor solubility, dissolution rate, and other physicochemical properties.Thus project had focused on the improvement of physicochemical properties of diacerein by co-crystal techniques.

\section{MATERIALS AND METHODS}

Diacerein obtained as a gift sample from Lupin Pharmaceutical Ltd, Mumbai, India. Urea and tartaric acid were purchased from SD Fine Chemical Mumbai. All the solvents used are of analytical grade and purchased from Qualigens, Mumbai.

\section{Preparation of co-crystal}

Co-crystal prepared with urea as coformer Pharmaceutical co-crystal of diacerein was prepared with different co-formers using solvent drop grinding methods. Diacerein-Urea co-crystal was prepared by grinding diacerein and urea in 1:1 molar ratio in a pestle and mortar for $90 \mathrm{~min}$ with the addition of few drops of ethanol (approximately $10 \%$ of weight). The solid powder was then scratched from walls of mortar and stored in a container ( Maski et al., 2009).

\section{Co-crystal prepared with tartaric acid as coformer}

Pharmaceutical co-crystal of diacerein was prepared with different co-formers using solvent drop grinding methods. DiacereinTartaric acid co-crystal was prepared by grinding diacerein and urea in 1:1 molar ratio in a pestle and mortar for $90 \mathrm{~min}$ with the addition of few drops of ethanol (approximately 10\% of weight). The solid powder was then scratched from walls of mortar and stored in container ( Maski et al., 2009).

\section{Micromeritic properties of co-crystal Melting point}

To determine the melting point of a cocrystal, a small amount of the sample is placed into a thin-walled capillary tube that is sealed at one end. The capillary tube is inserted into a melting point apparatus in which the temperature can be measured when heated (Deshmukh et al., 2010).

\section{Angle of repose}

It was determined by fixed funnel method. Accurately weighed quantity $(5 \mathrm{gm})$ of the sample was taken in a funnel; the height of the funnel is adjusted such that the tip of the funnel just touches the apex of the heap of the blend. Then the drug is allowed to flow through the funnel freely onto the surface. The diameter is then measured and angle of repose was calculated by following equation (Deshmukh et al., 2010).

\section{$\operatorname{Tan} \boldsymbol{\theta}=\mathbf{h} / \mathbf{r}$}

Where $\theta$ is the angle of repose, $\mathrm{h}$ is the height of the cone and $r$ is the radius of the cone base.

\section{Bulk density}

It was determined by pouring a weighed quantity $(5 \mathrm{gm})$ of the sample in to a graduated cylinder. The cylinder was dropped at $2 \mathrm{~s}$ interval on hard wood surface three times from the height of one inch. It was then calculated by the equation given below (Deshmukh et al., 2010).

$$
\text { Bulk density }=\frac{\text { the weight of the powder }}{\text { bulk volume }}
$$

\section{Tapped density}

It was determined by pouring a sample (5gm) in a measuring cylinder. The cylinder was dropped at $2 \mathrm{~s}$ interval on hard surface 100 times from the height of 1 inch. Then the final volume occupied by the drug was measured (Deshmukh et al., 2010).

$$
\text { Tapped density }=\frac{\text { weight of the blend }}{\text { final volume }}
$$

\section{Compressibility index}

The compressibility index (Carr's index) is a measure of a powder to be compressed.

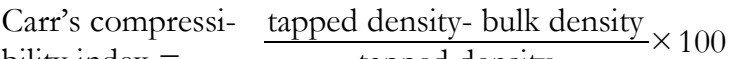
bility index $=\quad$ tapped density 


\section{Hausner ratio}

The Hausner ratio of powder was calculated according to the equation given below.

Hausner ratio $=\frac{\mathrm{Dt}}{\mathrm{Df}}$

Where, Dt $=$ tapped density, $\quad$ Df $=$ bulk density

\section{Characterization of co-crystal Infrared spectroscopy (FTIR)}

The co-crystals of Diacerein and commercial sample were scanned and recorded in the range of $4000-400 \mathrm{~cm}^{-1}$ by using an Infrared spectrophotometer, (Bruker, Alfa-T, Germany). The co-crystal samples were triturated with dried potassium bromide using mortar and pestle. The mixture after grinding into fine powder was kept uniformly in a suitable die and compressed into a pellet form by using a hydraulic press. The resultant pellet was mounted in a suitable holder in the IR spectrophotometer.

\section{Differential scanning calorimetry (DSC)}

After calibration, thermograms were obtained by heating $(5 \mathrm{mg})$ of commercial sample and its co-crystals prepared with coformer at a constant heating rate of $10^{\circ} \mathrm{C} / \mathrm{min}$ with chart speed of $20 \mathrm{~mL} / \mathrm{min}$ under an atmosphere of nitrogen. The exact peak temperatures, melting point and heat of fusion were automatically calculated. The temperature range for the scan was $20^{\circ} \mathrm{C}$ to $400^{\circ} \mathrm{C}$ for all the samples.

\section{Powder X-ray diffraction spectroscopy (PXRD)}

X-ray diffraction pattern of Diacerein and its various co-crystals prepared with coformer were obtained using the X-ray diffractometer (BRUKER D8 ADVANCE, Germany) at $40 \mathrm{kV}, 30 \mathrm{~mA}$ and a scanning rate of $1^{\circ} / \mathrm{min}$ at the diffraction angle $2 \theta$ over the range of $10-60^{\circ}$ using $\mathrm{Cu}$ (as anode) radiation of wavelength $1.5406 \mathrm{~A}^{\circ}$.

\section{Solubility and dissolution study Solubility studies}

Solubility of diacerein as well as co-crystal was studied in medium such as (distilled water). The excess quantity $(52.63 \mathrm{mg})$ of co-crystal was added in to glass stopper containing $50 \mathrm{~mL}$ of the medium at $37 \pm 0.5^{\circ} \mathrm{C}$ for $24 \mathrm{~h}$ on a magnetic stirrer at speed $150 \mathrm{rpm}$. Then the solution was filtered using Whatman filter paper no 1 . Appropriate dilution was made and concentration was determined spectrophotometrically (Shimadzu, Japan) at 340nm.

\section{Dissolution studies}

Dissolution studies of diacerein as well as co-crystal were perform using the USP dissolution test apparatus with basket rotating at $50 \mathrm{rpm}$ using $900 \mathrm{~mL}$ medium at $37 \pm 0.5^{\circ} \mathrm{C}$. Co-crystal equivalent to $50 \mathrm{mg}$ of diacerein were taken and filled in to capsule. The capsule was kept in basket \& dissolution was carried out for $60 \mathrm{~min}$ and the sample $(5 \mathrm{~mL})$ was withdrawn at 10, 20, 30, 40, 50,60min interval and the same volume was replaced to maintain sink condition. The absorbance of solution (after filtering through Whatman filter) was observed by using UV Spectrophotometer (Shimadzu, Japan) at 340nm (Nanajawade et al., 2012).

\section{Formulation of Co-crystals into Tablet}

Accurately weight quantity of co-crystal and various excipients such as lactose monohydrate, starch, and talc are properly mixed, following addition of magnesium sterates as lubricant. The powder mixture was subjected to compression in to tablet.

\section{Evaluation of tablet \\ Hardness}

The resistance of tablet during shipping to breakage, under condition of storage, transportation and handling before use depends on its hardness. For each formulation, the hardness of 3 tablets was determined using the Pfizer hardness tester. The tablet was held along its oblong axis in between two jaws of taster. At this point, reading should be zero $\mathrm{kg} / \mathrm{cm}^{2}$. Then constant force was applied until the tablet fractured. The value at this point was noted in $\mathrm{kg} / \mathrm{cm}^{2}$.

\section{Friability}

Friability is the measure of tablet strength. Electrolab friabilator was used for testing the friability. For each formulation, the friability of 20 tablets was determined. This test subjects a number of tablets to the combined 
effect of shock abrasion by utilizing the plastic chamber which revolves at the speed of $25 \mathrm{rpm}$, dropping the tablet to a distance of 6 inches in each revolution. A sample of pre-weight 20 tablets was placed in friabilator which was then operated for 100 revolutions i.e. $4 \mathrm{~min}$. tablets were then dedusted and reweight. A loss of less than $1 \%$ in weight is generally considered acceptable Percent friability $(\% \mathrm{~F})$ was calculated as follows

$\% \mathrm{~F}=\frac{\text { (Initial weight-Final weight) }}{\text { Initial weight }} \times 100$

\section{Weight variation test}

The weight variation test was done by taking 20 tablets and weight accurately. The average weight of tablet was calculated.

\section{Drug Content}

The drug content was carried out by taking 20 tablets and triturate. Take equivalent weight of powder $(5 \mathrm{mg})$ were dissolved in $5 \mathrm{~mL}$ dimethyl sulfoxide (DMSO) and volume was made up to $50 \mathrm{~mL}$ with water by sonicating for $15 \mathrm{~min}$. The solution was filtered through Whatman filter paper no.41. After appropriate dilutions with water it was analyzed spectrophotometricallyat $340 \mathrm{~nm}$ (Shimadzu 1800, Japan).

\section{Disintegration time}

The process of breakdown of a tablet into smaller particles is called as disintegration. The in-vitro disintegration time of a tablet was determined using disintegration test apparatus as per I.P. specifications. Place one tablet in each of the 6 tubes of the basket. Add a disc to each tube and run the apparatus using distilled water maintained at $37 \pm 2{ }^{\circ} \mathrm{C}$. The assembly should be raised and lowered between 28 to 32 cycles per minute in the distilled water maintained at $37 \pm 2{ }^{\circ} \mathrm{C}$. The time minute taken for complete disintegration of the tablet with no palpable mass remaining in the apparatus was measured and recorded

\section{RESULT AND DISCUSSION Preparation of Co-crystal}

Diacerein showed good solubility in Dimethyl-sulfoxide. It was practically insoluble in distilled water, ethanol, methanol, chloroform, ethyl acetate, and acetone. Thus co-crystals were prepared by solvent drop grinding method using ethanol as a solvent of choice because of its easy availability, cheaper in cost as well as coformer is soluble. Diacerein co-crystal was prepared by simple solvent drop grinding method because amongst its other methods like Solution co-crystallization, slurry conversation, anti solvent addition fails formation of co-crystal due to its solubility problem hence this method has use for formation of co-crystal in presence of cOformer such as Urea, Tartaric acid with 1:1 molar ratio. The coformer has selected by its selection criteria high water solubility, hydrogen bond donor \& acceptor group. These newly formed Co-crystals along with the pure drug were subjected to further characterization and various evaluation tests such as solubility, dissolution, etc.

The values of micromeritic properties were mentioned in the table I. The values indicates, that prepared co-crystals showed good flowability as well as compressibility. The angle of repose of co-crystals prepared with urea and tartaric acid showed $27.08 \pm 085$ and $28.77 \pm 0.586$ respectively compared to commercial diacerein $36.75 \pm 0.303$, indicates improvement in the flowability.

The bulk and tapped density value of cocrystals prepared with urea and tartaric acid showed $0.363 \pm 0.016, \quad 0.346 \pm 0.024$ and $0.436 \pm 0.02,0.423 \pm 0.01$ respectively considered to commercial diacerein $0.331 \pm 0.012$ and $0.391 \pm 0.02$ showed good compactibility.The Carr's index and Hausners ratio values also supports the flowability and compressibility of diacerein.

\section{Characterization of co-crystals Infrared spectroscopy}

Characteristic peaks of Diacerein appeared at $1417.68 \mathrm{~cm}^{-1} \quad(\mathrm{C}=\mathrm{C}$ stretching), $1668.43 \mathrm{~cm}^{-1}$ (C=O stretching), $1026.1 \mathrm{~cm}^{-1}$ (C$\mathrm{O}-\mathrm{C}$ stretching) and $1369.46 \mathrm{~cm}^{-1}$ (Acidic $\mathrm{OH}$ ) were observed. IR spectra of commercial drug when compared with the various Co-crystals of Diacerein obtained in the presence of coformer shows slight change in their characteristic peaks because due to the by donating and accepting hydrogen to form the hydrogen bonding in 
Table I. Micromeritic properties of co-crystal

\begin{tabular}{lcccccc}
\hline Formulation & $\begin{array}{c}\text { Angle of } \\
\text { Repose }\end{array}$ & $\begin{array}{c}\text { Bulk } \\
\text { density }\end{array}$ & $\begin{array}{c}\text { Tapped } \\
\text { density }\end{array}$ & $\begin{array}{c}\text { Carr's } \\
\text { index }\end{array}$ & $\begin{array}{c}\text { Hausner's } \\
\text { ratio }\end{array}$ & $\begin{array}{c}\text { Melting } \\
\text { Point }\end{array}$ \\
\hline \multirow{2}{*}{ Pure Drug } & 36.75 & 0.331 & 0.391 & 14.45 & 1.37 & $217^{\circ} \mathrm{C}$ \\
& \pm 0.303 & \pm 0.012 & \pm 0.02 & & & \\
Drug-urea co-crystal & 27.08 & 0.363 & 0.436 & 11.96 & 1.25 & $150^{\circ} \mathrm{C}$ \\
& \pm 0.805 & \pm 0.016 & \pm 0.02 & & & \\
Drug-TA co-crystal & 28.77 & 0.346 & 0.423 & 11.20 & 1.27 & $177^{\circ} \mathrm{C}$ \\
\hline
\end{tabular}

Table II. FTIR data of pure drug \& co-crystal

\begin{tabular}{clcccc}
\hline $\begin{array}{c}\text { Sr. } \\
\text { no }\end{array}$ & \multicolumn{1}{c}{ Crystal codes } & $\begin{array}{c}\text { C=C } \\
\text { stretching }\end{array}$ & $\begin{array}{c}\text { C=O } \\
\text { stretching }\end{array}$ & $\begin{array}{c}\text { C-O-C } \\
\text { stretching }\end{array}$ & $\begin{array}{c}\text { O-H } \\
\text { Stretching }\end{array}$ \\
\hline 1 & Pure drug & 1417.68 & 1668.43 & 1026.13 & 1369.46 \\
2 & Drug-urea co-crystal & 1435.04 & 1678.07 & 1157.29 & 1255.56 \\
3 & Drug-TA co-crystal & 1450.47 & 1693.5 & 1193.94 & 1290.38 \\
\hline
\end{tabular}

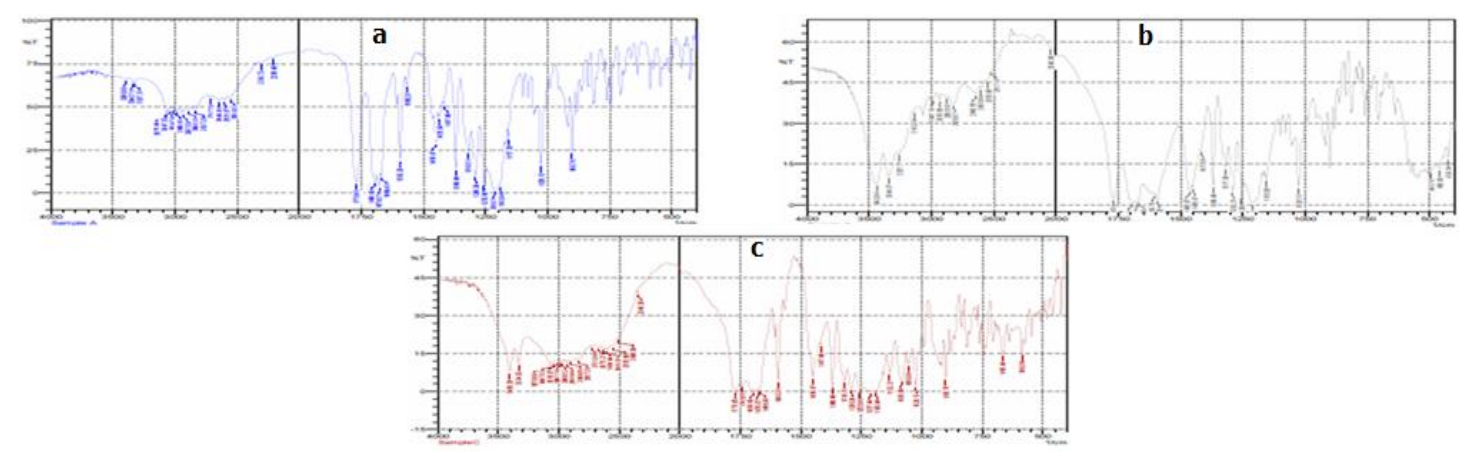

Figure 1. (a)FTIR spectra of pure drug (Diacerine), (b) FTIR spectra of Drug-urea co-crystal, (c) FTIR spectra of Drug-TA co-crystal

drug and coformer. These results indicated that there is slight interaction between drug and coformer when formed as co-crystals,

\section{Differential scanning calorimetry}

All the co-crystals prepared by solvent drop grinding method showed characteristic endothermic peak of diacerein. DSC is showed usually co-crystal composition of pharmaceutical powders, when the co-crystal presents different melting points. The thermal behaviour of commercial diacerein and co-crystals are shown below. The DSC curve showed that Diacerein appeared on sharp endothermic peak at about $236.0^{\circ} \mathrm{C}$ corresponding to its melting point. However the co-crystals obtained with urea and tartaric acid as coformer showed the shift of endothermic peak towards lower temperature at $133.6^{\circ} \mathrm{C}$ and $170.2^{\circ} \mathrm{C}$ respectively. Shift of endothermic peak towards lower temperature indicates the decrease in the melting point of drug in co-crystals. This decreased melting point accounts for increased solubility of drug.

\section{Powder X-ray diffraction}

The X-ray diffraction pattern of various co-crystalwere studied by X-ray diffractometer. The X-ray diffraction pattern of pure drug has more number of peaks when compared to various co-crystals. XRD spectra of drugtartaric acid co-crystal have decreased number of peaks but increase in intensity was observed. The XRD spectra of drug-urea co-crystal have increase in the intensity of peaks. Characteristic 
Table III. DSC data of pure drug and modified co-crystals

\begin{tabular}{clccc}
\hline \multirow{2}{*}{$\begin{array}{l}\text { nr. } \\
\text { no. }\end{array}$} & Crystal form & \multicolumn{3}{c}{ DSC data } \\
\cline { 3 - 4 } & & $\begin{array}{c}\text { Melting point } \\
\left.\mathbf{(}{ }^{\circ} \mathbf{C}\right)\end{array}$ & $\begin{array}{c}\text { Peak fusion point } \\
\left({ }^{\circ} \mathbf{C}\right)\end{array}$ & $\begin{array}{c}\text { Heat of fusion } \\
(\mathbf{J} / \mathbf{g})\end{array}$ \\
\hline 1 & Pure drug & 238.5 & 236.0 & 36.73 \\
2 & Drug-urea co-crystal & 137.5 & 133.6 & 129.8 \\
3 & Drug-Tartaric acid co- crystal & 174.4 & 170.2 & 138.4 \\
\hline
\end{tabular}
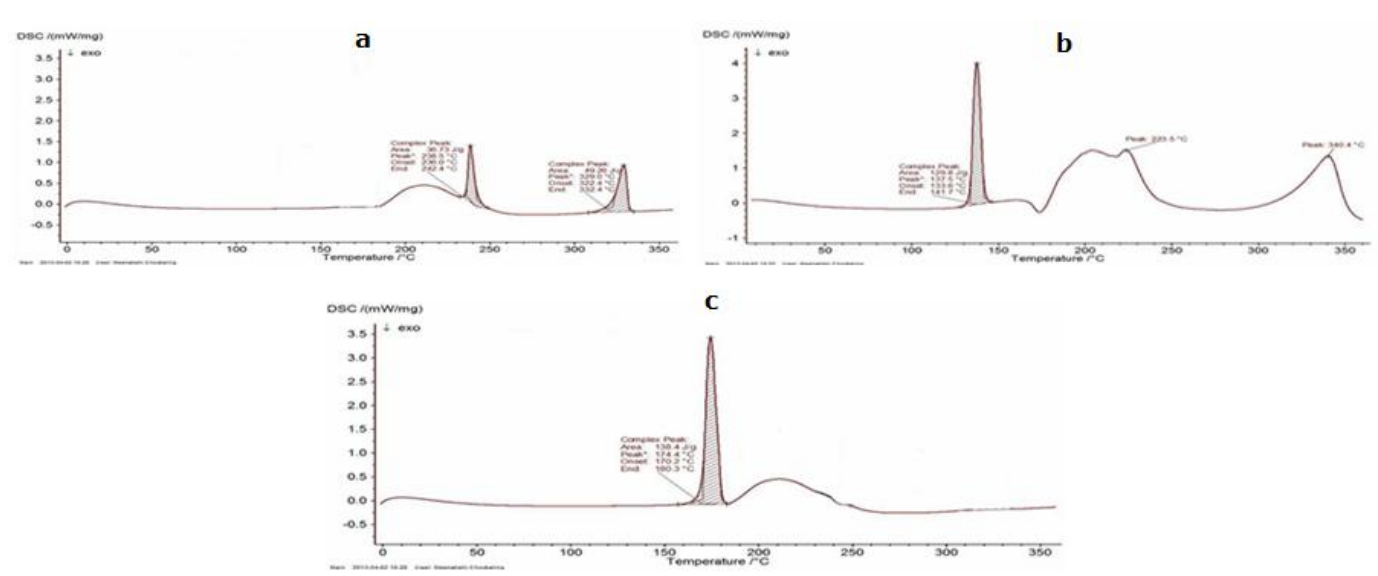

Figure 2. (a) DSC Thermogram of pure drug (Diacerein), (b) DSC Thermogram of DrugUrea co-crystal, (c) DSC Thermogram of Drug-tatartaric acid co-crystal

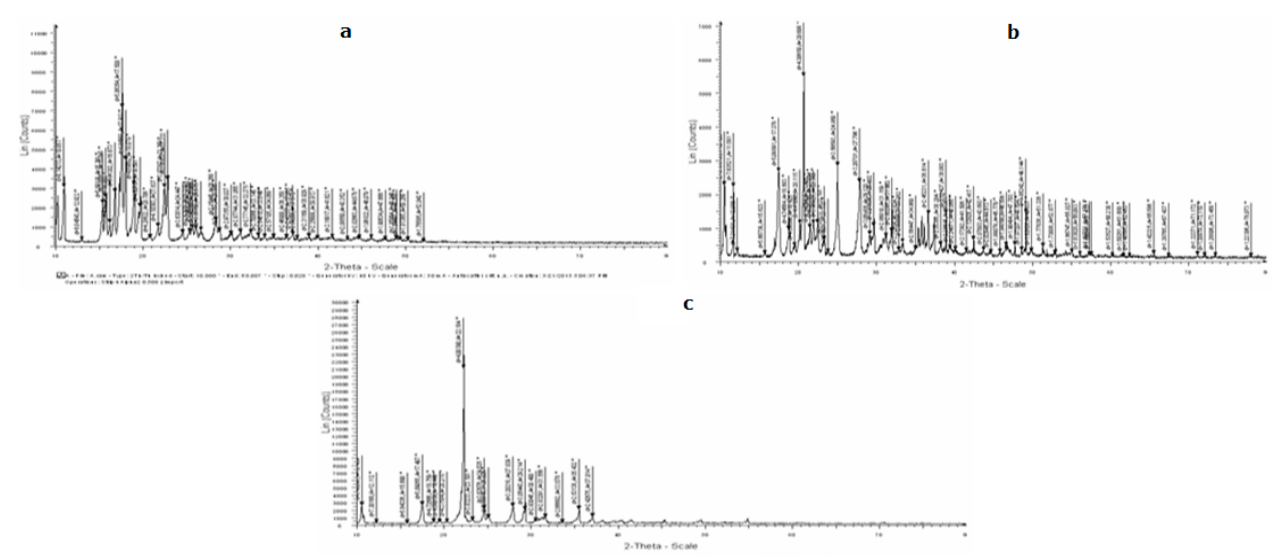

Figure 3. (a) XRD Spectra of pure drug (Diacerein), (b)XRD Spectra of Drug-Urea cocrystal, (c) XRD Spectra of Drug-Tartaric acid co-crystal

diffraction peaks were observed at $2 \theta=$ 15843 and 16673. The XRD spectra of Pure drug and co-crystals obtained in presence of co-crystal coformer exhibited essentially similar diffraction patterns (20 values), suggesting that particles crystallized in the presence of co-coformer by solvent drop co- grinding method did not undergo structural modification.

However, the differences in the relative intensities of their peaks may be attributed to differences in the crystal size and habits of the sample, which may be attributed to the different solubility of the drug in the media. 


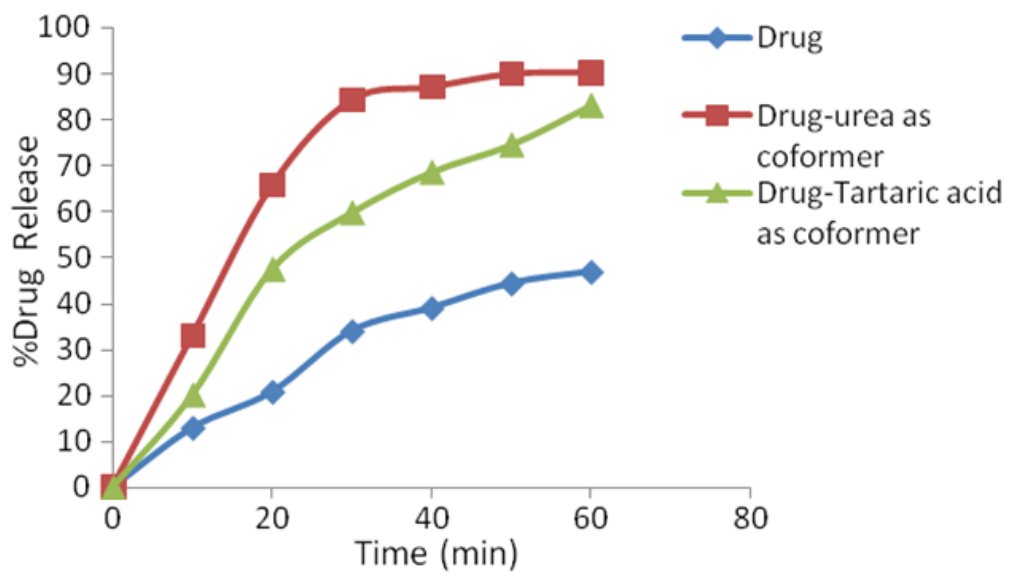

Figure 4. Dissolution study of Diacerein co-crystal

Table IV. Post compression parameter

\begin{tabular}{|c|c|c|c|c|c|}
\hline Formulation & $\begin{array}{l}\text { Hardness } \\
(\mathrm{Kg} / \mathrm{cm} 2)\end{array}$ & $\begin{array}{c}\text { Friability } \\
(\%)\end{array}$ & $\begin{array}{c}\text { Weight } \\
\text { Variation }\end{array}$ & $\begin{array}{l}\text { Drug Content } \\
(\mathrm{W} / \mathrm{W})\end{array}$ & $\begin{array}{c}\text { Disintegration } \\
\text { Time (Sec) }\end{array}$ \\
\hline Drug & $4.7 \pm 0.4$ & $0.453 \pm 0.15$ & Passed & $98.23 \pm 0.02$ & $190 \pm 3$ \\
\hline Drug-urea co-crystal & $4.5 \pm 0.35$ & $0.410 \pm 0.10$ & Passed & $98.05 \pm 0.95$ & $182 \pm 2$ \\
\hline Drug-T.A co-crystal & $5.1 \pm 0.55$ & $0.443 \pm 0.08$ & Passed & $99.09 \pm 1.01$ & $153 \pm 1$ \\
\hline
\end{tabular}

\section{Solubility studies}

The solubility study showed that the pure drug Diacerein was the least soluble $(2.625 \mu \mathrm{g} / \mathrm{mL})$ and the co-crystals grown in presence of urea as coformer was soluble $(21.0 \mu \mathrm{g} / \mathrm{mL})$ with 7.84 -fold increase in solubility and the co-crystal in presence of tartaric acid was soluble $(13.125 \mu \mathrm{g} / \mathrm{mL})$ with 4.80-fold increase solubility, The increase in the solubility of co-crystals due to melting of coformer which are associated with the co-crystals when compared to pure drug (Diacerein).

\section{Dissolution studies}

The dissolution curves of the different co-crystals showed differences in the rate of dissolution. The result of dissolution studies are presented as percent release vs. time. The highest dissolution rate was found for the drug-urea co-crystal. The dissolution rate cocrystal in presence of Urea, Tartaric Acid as coformer showed $91.31 \%$ and $83.13 \%$ compared to commercial diacerein $46.88 \%$ in $60 \mathrm{~min}$.
The general appearance of tablets, its visual identity and overall elegance is essential for acceptability, the shape of all the formulation remained off white, smooth, flat faced circular and no visible cracks. The friability was measured by Roche friabilator and was found to be drug- $0.453 \%$, Drugurea co-crystal $0.410 \%$, Drug-Tartaric acid cocrystal $0.443 \%$ friability and this parameter given the satisfactory mechanical resistance of the tablet.

The entire tablet passed the weight variation test as the weight variation was within the pharmacopoeias limits of $7.5 \%$ of the weight.

Percentage drug contents of prepared co-crystals were found to be in the range of $98.05 \pm 0.95 \mathrm{w} / \mathrm{w}$ to $99.09 \pm 1.01 \mathrm{w} / \mathrm{w}$. Disintegration time of tablet formulation was found to be in the range $153 \pm 1$ to $190 \pm 3$ s.

\section{CONCLUSION}

Diacerein co-crystal was successfully prepared by solvent drop method. Solubility and dissolution rate of co-crystals were 
markedly increased compared to untreated Diacerein. Thus the co-crystals techniques were helpful to improve the physicochemical properties of Diacerein.

\section{ACKNOWLEDGEMENT}

The Authors are thankful to the Management and Principal, IBSS College of Pharmacy, Malkapur for providing necessary facilities to carried out this work. Authors also thankful to Diya Labs, Mumbai and AISSMS College of Pharmacy, Pune for providing SEM, FTIR, XRD and DSC facilities repectively.

\section{REFERENCE}

Deshmukh DB. et al,. 2010, Dissolution Enhancement of Poorly Water Soluble Diacerein By Solid Dispersion Technique. J. Pharm. Sci. Res. 2;734-739.

Gagniere E., Margin D., Puel P., Rivoire A., Monnier O. 2009, Formation of cocrystal kinetic and thermodynamic aspects. J.Crystal Growth;11; 2689-2695.

Hickey M., Peterson M., Scoppettuolo L., Morrisette S. 2007; Performance comparison of co-crystal of Carbamazepine with marketed product, Eur. J Pharm. Biopharm., 67; 112-119.

Harry G., Brittain. 2006, Polymorph in Pharmaceutical solids. Mercel Dekeker publication, 7;1-2.

Lachman L., Lieberman H., 1991, The theory and practice of Industrial Pharmacy. Third Editon; Varghese publishing house, 3:180.

Mahajan A., Singh K., Tandon VR., 2006, Diacerein: A New Symptomatic Slow
Acting Drug for Osteoarthritis. JK Sci, 8;173-75.

Nanjwade VK., Shulka VK., Manvi FV. 2012, Development and characterization of novel pharmaceutical Crystalline complex of lomefloxacin. Int. J. Drug Dev. Res; 1;227-33.

Maski N., Arul K., 2009, Studies on the preparation, characterization and solubility of Cyclodextrendiacerein complex. Int J Pharm and Sci 1;121-35.

Saifee M., Inamdar N., Dhamecha D., 2009.; Drug polymorphism review; Int. J. Health research, 2;291-366.

Anindita S., Sohrab R., 2014,Co-crystals of Acyclovir with promising physicochemical properties, J. Pharma. Sci, Vol-104, Issue-1; 98-105.

Shital S., Shete AS., Doijad RC., Kadam SS., Patil VA., Yadav AV., 2015, Formulation and Solid State Charac-terization of Nicotinamide-based Co-crystals of Fenofibrate.Ind. Jr. Pharm. Sci. 77(3); 328334.

Subhrahmanyam CVS., Thima SA., Devi SK., 2000, Pharmaceutical engineering principle and practices. Vallabhprakashan,; 42.

Vippagunta SR., Brittan H., Grant G. 2001, Crystalline solids Advanced drug Delivery reviews, pp 48; 3-26.

Yadav DS., 2012, Preparation and characterization of Diacerein microcrystall. Der Pharmacia Lettre, 4;428-435.

Zhou Z., Li W., Sun W-Z., 2016, Resveratrol cocrystals with enhanced solubility and tabletability, J. Pharma. Sci, Vol-509, Issue-1-2; 391--399. 